\title{
Ambiente virtual de aprendizagem e educação presencial: uma integração possível na formação de professores
}

\author{
Virtual learning environment and school \\ attendance: a possible integration in teachers' \\ education
}

\author{
Ettiène Guérios* \\ Sandra Sausen ${ }^{* *}$
}

\begin{abstract}
Resumo: Este artigo apresenta resultado de pesquisa sobre processos de interação e mobilização identificadas em alunos de um curso presencial de Licenciatura em Matemática usando recursos de ambientes virtuais de aprendizagem. O recorte neste artigo se dá sobre a mobilização de conhecimentos curriculares numa perspectiva de prática pedagógica em interações estabelecidas com o uso do chat e do diário. A análise teve por base Thompson (2004), Primo (2008), Silva (2010), Scherer (2005), Charlot (2000), entre outros. Os resultados mostram que houve mobilização de conhecimentos através de interações mútuas e a existência de um movimento reflexivo de aprendizagem que implicou construção conceitual, que a integração das ferramentas disponíveis em ambientes virtuais no ensino presencial potencializam a comunicação e a interação entre professor e aluno e entre os alunos, estendendo os processos de aprendizagem para além do espaço e do tempo das aulas, dando a ideia de uma "sala de aula expandida".
\end{abstract}

Palavras-chave: Ambientes virtuais de aprendizagem. Educação Matemática. Formação de professores.

\begin{abstract}
This paper presents the result of a study on processes of interaction and mobilization identified in students in a Mathematics Degree attendance course using resources from the virtual learning environment. The focus of this study is on the mobilization of curricular knowledge under a perspective of pedagogical practice in interaction established with the use of chat and diary. The analysis was based on Thompson (2004), Primo (2008), Silva (2010), Scherer (2005), Charlot (2000), among others. Results reveal that there was mobilization of knowledge through mutual interactions and the existence of a learning reflective movement which implied
\end{abstract}

\footnotetext{
* Professora da Universidade Federal do Paraná. E-mail: <ettiene@avalon.sul.com.br>

** Professora da Rede Estadual de Ensino do Estado do Paraná. E-mail: <sansausen@gmail.com>
} 
conceptual construction, that the integration of tools available in virtual environments to the attendance environment optimized communication and the interaction between teacher students and among students, broadening the learning processes beyond the space and time of lessons, creating the effect of an 'expanded classroom'.

Keywords: Virtual learning environments. Mathematical Instruction. Teachers' Education.

\section{Introdução: anúncio de uma questão de investigação}

Iniciamos este artigo com um dizer de Moran (2002, p. 1) que nos é provocativo, instigante e nos faz extrapolar as fronteiras da sala de aula no ensino presencial quando pensamos em prática pedagógica: “[...] o presencial se virtualiza e a distância se presencializa”. Acreditamos que se este dizer for verdadeiro em circunstância didática em que recursos disponíveis em ambientes virtuais sejam utilizados no ensino presencial, então, como corolário podemos dizer que o espaço de trocas inter-sujeitos e entre alunos, professores e conhecimento curricular se estende além da sala de aula. Moran (2004, s. p.) afirma que as tecnologias de informação e comunicação (TIC) possibilitam “[...] aprender estando juntos em lugares distantes, sem precisarmos estar sempre juntos numa sala para que isso aconteça". Esta afirmação nos sensibiliza tendo em vista sua amplitude, por abranger os professores da universidade formadores de professores, os seus alunos, futuros professores em formação e também os seus alunos, jovens da Educação Básica. Não é demais ter em mente o fato, hoje já senso comum, de que as crianças já nascem num mundo tecnológico, que nossos jovens operam os recursos da informática com tal presteza e naturalidade, que lhes é natural tanto a manipulação quanto o adentramento num mundo em que relações entre pares são estabelecidas virtualmente, posto que pensam numa lógica operante própria do mundo informatizado em que se constituem sujeitos - e passam pelos bancos universitários dos cursos de licenciatura.

Parece que os tempos atuais estão anunciando a possibilidade de haver uma simbiose entre espaço virtual e espaço presencial na esfera educativa, oportunizando, como consequência, a ocorrência de práticas didáticas inovadoras, assim como de processos autônomos e particulares de aprender. É a prática pedagógica, em suas diferentes nuances, que pode estar no limiar da operacionalidade técnica vigente, respeitando-se a construção individual de estratégias de pensamento em particularidades do aprender.

Em nosso ponto de vista, não se trata de defender a mera incorporação de equipamentos, recursos ou novos métodos, por si, como inovação na prática pedagógica. Inovação haverá se esta incorporação estiver vinculada à modificação da performance didática do professor. A história já mostrou que 
mudanças operacionais ou de metodologia de ensino sem foco na construção de uma prática pedagógica situada, pouco contribuem com a melhoria do ensino e com a qualidade da aprendizagem ${ }^{1}$. Sá (2007) bem observa que as TIC não modificam necessariamente a prática pedagógica, pois elas tanto podem servir para reforçar uma visão conservadora, individualista, autoritária, como para embasar uma visão emancipadora, aberta, interativa e participativa. "Nesse caso, transgredir a relação está mais na mente das pessoas do que nos recursos tecnológicos, embora sejam inegáveis suas potencialidades pedagógicas" (SÁ, 2007 , p. 8). Nesse sentido, compactuamos com Scherer (2005, p. 46) que “[...] educar é ousar, existir na complexidade, na busca contínua da compreensão do desconhecido, questionando e se alimentando da incerteza, participando da história, construindo-a." Complementando com Guérios (2002, p. 164) temos:

[...] se a prática pedagógica é realizada por sujeitos humanos, então não há como deixar de reconhecer que objetividade, subjetividade, razão e emoção fundem-se, formando um todo único e complexo, que não admite fórmulas mágicas para efetivar-se. É nesse contexto que o professor se constitui pela sua experiência, em sua caminhada, a qual comporta certezas e incertezas, o previsível e o imponderável, o conhecido e o desconhecido.

Reflexões que efetivamos e estudos teóricos que desenvolvemos nos levam a pensar em possíveis efeitos da integração na educação presencial de recursos que a educação a distância incorporou como indispensáveis numa realidade educativa em que espaço e tempo não necessariamente são contíguos. Utilizamos o termo integração e não inserção das TIC às práticas pedagógicas por compactuarmos com Bittar (2010) que o termo "inserção da tecnologia na educação" é referente ao uso esporádico que se faz de recursos didáticos, em uma ou outra aula, desvinculados da prática pedagógica dos professores. A integração das TIC ao processo pedagógico acontece quando o professor utiliza diversos recursos, diversas tecnologias (digitais ou não) com o intuito de auxiliar o aluno na construção do pensamento matemático e, em nosso caso, do pensamento pedagógico, tendo em vista que os sujeitos da pesquisa são futuros professores.

Ao mencionarmos recursos incorporados pela educação a distância nos remetemos a ambientes virtuais, entendidos aqui como os espaços desenvolvidos através de recursos computacionais que propiciem processos de ensino e de aprendizagem por meio do uso das TIC via web e por Ambiente Virtual de Aprendizagem (AVA), o que permite "[...] integrar múltiplas mídias,

\footnotetext{
${ }^{1}$ Guérios (2002) constatou que métodos, recursos ou conhecimentos que são oferecidos verticalmente ao professor sem que haja identificação entre ele e o que lhe é oferecido ou são aceitos para resolver problemas imediatos sem que haja modificação qualitativa de sua prática pedagógica, ou são rejeitados.
} 
linguagem e recursos, apresentar informações de maneira organizada, desenvolver interações entre pessoas e objetos de conhecimento, elaborar e socializar produções tendo em vista atingir determinados objetivos" (ALMEIDA, 2003, p. 331). Para Schlemmer (2002), ambientes virtuais de aprendizagem são espaços desenvolvidos através de recursos computacionais para amparar processos de ensino e de aprendizagem por meio do uso das TIC via web. A fim de caracterizar esse espaço, Bairral (2007, p. 17) embasa-se em Duart e Sangrá (1999), dizendo que ambientes virtuais de aprendizagem "[...] devem possibilitar flexibilidade, interatividade, inserção e vinculação na comunidade virtual constituída, e permitir aos envolvidos o acesso a materiais e demais fontes de recursos disponíveis na rede." A plataforma que utilizamos é a Moodle².

Foi nesse contexto que nasceu a presente questão de investigação.

Nesta pesquisa investigamos possibilidades de interação e mobilização de conhecimentos curriculares, matemáticos e pedagógicos, a partir da Resolução de Problemas que podem ser identificadas em alunos de um curso presencial de Licenciatura em Matemática, utilizando recursos de ambientes virtuais de aprendizagem nas aulas de Metodologia do Ensino. Temáticas específicas nortearam o processo investigativo, entre elas: o modo como os ambientes virtuais podem potencializar processos de interação, auxiliando no ensino e na aprendizagem em cursos presenciais de Licenciatura em Matemática; o tipo de interações que esses alunos estabelecem com os colegas e com o conhecimento matemático ao fazer uso do chat, como o uso do chat e do diário podem contribuir para o estabelecimento de conexões entre o conhecimento teórico e a prática.

No decorrer das atividades para a coleta dos dados empíricos, foram identificadas e analisadas atitudes e ações dos alunos que favorecem a aprendizagem e a comunicação em uma proposta de utilização dos recursos disponíveis em ambientes virtuais no ensino presencial. Observamos situações didáticas ${ }^{3}$ que ocorreram no processo de formação inicial em um contexto especí-

\footnotetext{
${ }^{2}$ A palavra Moodle teve origem no acrônimo: Modular Object-Oriented Dynamic Learning Environment, que é informativo especialmente para programadores e investigadores educativos. (Disponível em: <http://docs. moodle.org/pt/Sobre_o_Moodle>. Acesso em: 5 fev. 2010). Foi desenvolvida em 1999, na Curtin University of Technology, em Perth, na Austrália, com o objetivo de fomentar um espaço de colaboração, onde os seus usuários poderiam trocar conhecimentos, experimentando, criando novas interfaces para o ambiente em uma grande comunidade aberta.

${ }^{3}$ Nesta pesquisa entendemos por situações didáticas: situações de aprendizagem; situações de desconforto pela exposição ao novo o que pode inibir a aprendizagem; situação de conforto por sentir-se menos exposto do que em sala de aula (de certa forma a face estará oculta), mas podendo expressar-se [através da escrita] expondo suas ideias. "É possível que tímidos-presenciais sejam falantes-virtuais, e que haja aqueles que preferem se expor tendo a internet como mídia e outros que prefiram somente como interface o ar que circula nas salas de aula." (BORBA; MALHEIROS; ZULATTO, 2007, p. 91). Para Brousseau (2009), uma situação didática é formada pelas múltiplas relações pedagógicas estabelecidas entre professor, alunos e o saber, com a finalidade de desenvolver atividades voltadas para o ensino e para a aprendizagem de conteúdos.
} 
fico, mediadas pela reflexão individual e partilhada coletivamente na disciplina de Metodologia do Ensino de Matemática. Esse processo de reflexão ocorreu durante atividades com resolução de problemas ${ }^{4}$ realizadas no espaço presencial (sala de aula) e, também, com a utilização de recursos disponíveis no espaço virtual (chat e diário) com a temática Resolução de Problemas como metodologia para o ensino de Matemática.

\section{Caminho Metodológico}

Esta pesquisa foi qualitativa, de natureza exploratório-interpretativa. Qualitativa porque, de acordo com Bicudo (2006, p. 107), é a modalidade em que

[...] privilegiam-se descrições de experiências, relatos de compreensões, respostas abertas a questionários, entrevistas com sujeitos, relatos de observações e outros procedimentos que dêem conta de dados sensíveis, de concepções, de estados mentais, de acontecimentos.

De natureza exploratório-interpretativa porque, de acordo com Alves-Mazzotti e Gewandszbajder (2001, p. 131), estas pesquisas “[...] partem do pressuposto de que as pessoas agem em função de suas crenças, percepções, sentimentos e valores e que seu comportamento tem sempre um sentido, um significado que não dá a conhecer de modo imediato, precisando ser desvelado". Ainda, segundo Myers (2012), interpretativa porque busca compreender o fenômeno a partir dos próprios dados, das referências fornecidas pelos sujeitos.

Os sujeitos da pesquisa foram alunos da disciplina Metodologia do Ensino de Matemática, do quarto ano de um Curso de Licenciatura em Matemática na modalidade presencial, período noturno, nos anos de 2009 e 2010, de uma instituição pública de Ensino Superior. A maioria dos alunos concluiu o Ensino Médio em escolas públicas, são trabalhadores e não atuam no magistério. Possuem conhecimentos elementares de informática, mas nem todos têm computador com acesso à internet em suas residências. Nenhum deles tinha conhecimento da plataforma Moodle e seus recursos chat e diário.

Atividades de intervenção foram realizadas em três etapas, no espaço presencial e no virtual. A primeira etapa foi no espaço presencial - na sala de aula - e os alunos resolveram problemas matemáticos com enunciados propostos pelas pesquisadoras. A segunda etapa foi no virtual - com os recursos chat e diário, disponíveis no Ambiente Virtual de Aprendizagem (AVA) - onde os alunos mobilizaram conhecimentos e identificaram, na resolução que efetivaram

\footnotetext{
${ }^{4}$ Quando a referência for à metodologia de Resolução de Problemas, será utilizada a expressão Resolução de Problemas com as iniciais maiúsculas e, quando for ao ato de resolver problemas ou situações-problema, a referida expressão será escrita em letras minúsculas.
} 
dos problemas, fundamentos teóricos dos conteúdos curriculares que haviam desenvolvido na disciplina Metodologia do Ensino de Matemática, relativos ao conteúdo curricular Resolução de Problemas, numa perspectiva de prática pedagógica.

A terceira etapa foi o retorno ao espaço presencial - sala de aula, em que os alunos discutiram as resoluções e aprofundaram as discussões teóricas. Esta etapa ocorreu para que dados empíricos complementares possibilitassem uma análise conexa de relações conceituais estruturantes dos conteúdos pedagógicos que os sujeitos da pesquisa estabeleceram no espaço virtual, na apreensão dos conteúdos curriculares da disciplina Metodologia do Ensino de Matemática, os quais foram foco de observação de aprendizagem no processo de investigação de ocorrência da interação face a face e da interação mediada (THOMPSON, 2004; PRIMO, 2008), considerando-se a interação mútua e a interação reativa (PRIMO, 2008).

Os dados empíricos foram obtidos com as seguintes ações: observação in loco dos alunos durante o desenvolvimento de atividades no espaço presencial, gravação em áudio desses momentos, transcrições dos diálogos estabelecidos entre os alunos durante as atividades, análise dos registros escritos durante a atividade desenvolvida no espaço presencial; análise dos registros das atividades desenvolvidas no espaço virtual com a utilização das ferramentas digitais chat e diário, disponíveis no AVA “Curso: Educação Matemática”, hospedado na plataforma Moodle, observação dos alunos nas atividades em grupo, gravação em áudio e transcrições dos diálogos estabelecidos entre os alunos.

Os dados empíricos foram interpretados e analisados à luz de referenciais teóricos na confluência de parâmetros do campo da metodologia de ensino com foco na Resolução de Problemas e na utilização de ferramentas disponíveis em ambientes virtuais no ensino presencial. A análise que se deu na interseção destas relações (ferramentas digitais do AVA Moodle, educação presencial e metodologia de ensino) com as categorias criadas permitiram responder à questão da investigação. Para a análise das possibilidades de interação ocorridas durante o desenvolvimento das atividades, teve-se embasamento teórico em Thompson (2004), que aborda a questão comunicacional da interação e argumenta sobre o potencial dialógico nos meios tradicionais, em que parte da interação face a face e a contrasta com a interação mediada. Houve amparo nos estudos de Silva (2010) que sistematizou o mapeamento de especificidades e singularidades de interatividade destacando três binômios de aspectos distintos que combinam e dialogam e que não são independentes: participação-intervenção, bidirecionalidade-hibridação e permutabilidade-potencialidade. Prado e Rosa (2008, p. 174, grifo das autoras) mencionam que: 
Na interatividade, a "ação" ganha destaque em sua própria essência conceitual: inter-ação. No hipertexto e as novas modalidades comunicacionais (chats, MSN, Orkut etc.), há uma fusão de papéis e de funções que vão além do ato de troca, possibilitando novas formas de comunicação e, portanto, de participação.

O referencial teórico possibilitou elencar duas categorias de análise. A primeira categoria de análise foi "interação", subdividida em duas subcategorias interação face a face (THOMPSON, 2004) e interação mediada (THOMPSON, 2004; PRIMO, 2008); na interação mediada, investigamos a ocorrência da interação mútua e da interação reativa (THOMPSON 2004; PRIMO, 2008). A estruturação dos dados empíricos obtidos fomentou a criação da segunda categoria de análise, resultante de circunstâncias que deles emergiram. A segunda categoria de análise foi "mobilização" em que investigamos a mobilização de conhecimentos do conteúdo Resolução de Problemas, da disciplina de Metodologia do Ensino de Matemática, e a mobilização do sujeito para aprender (CHARLOT 2000).

\section{Comunicação, interação, atividade: mobilização teórica}

Para a análise das possibilidades de interação e mobilização ocorridas durante o desenvolvimento das atividades, buscamos aporte teórico em Thompson (2004) e em Primo (2008) por abordarem a questão comunicacional da interação e de argumentar sobre o potencial dialógico em diferentes meios. Em Silva (2010) que sistematizou o mapeamento de especificidades e singularidades de interatividade. Em Prado e Rosa (2008) que abordam sobre papéis e funções das modalidades comunicacionais em situações interativas. Em Charlot (2000), que apresenta um conceito de mobilização de conhecimento e de postura pessoal. No percurso de construção teórica dialogamos também com Kenski (2003) e com Scherer (2005).

No decorrer dos estudos teóricos, sentimo-nos provocadas por uma afirmação de Charlot (2000). Ao discutir sobre o inacabamento do ser, afirma que, para construir-se, o sujeito deve ir apropriando-se de uma humanidade que the é "exterior", o que implica a mediação do outro. "A educação não é subjetivação de um ser que não seria sujeito; o sujeito está sempre aí. A educação não é socialização de um ser que não fosse já social: o mundo, e com ele a sociedade, já está sempre presente.” (CHARLOT, 2000, p. 54). Esta afirmação cabe no centro da esfera educativa, se nela pensarmos, de fato, numa perspectiva de Educação. O sujeito, em permanente construção, ou seja, em desenvolvimento, pertence a um tempo, habita espaços e desenvolve atividades. Assim é no interior dos cursos de licenciaturas, em que se faz professor que vai atuar com crianças e 
jovens, seres em desenvolvimento, em etapa de construção de seus conhecimentos curriculares, de seus valores éticos e morais, de seus conhecimentos para a vida, experiencialmente.

Segundo o autor, para haver atividade, o sujeito deve mobilizar-se, mas para que ele se mobilize, a situação deve ser significativa, ter um sentido para ele. Charlot (2000) desenvolve três conceitos quando trata da relação do sujeito com o saber: mobilização, atividade e sentido.

Interessa-nos, diretamente, a abordagem de Charlot (2000, p. 54-55, grifo do autor) referente à mobilização:

O conceito de mobilização implica a ideia de movimento. Mobilizar é pôr em movimento; mobilizar-se é pôr-se em movimento. Para insistir nessa dinâmica interna é que utilizamos o termo de "mobilização", de preferência ao de "motivação". A mobilização implica mobilizar-se ("de dentro"), enquanto que a motivação enfatiza o fato de que se é motivado por alguém ou por algo ("de fora”). É verdade que, no fim da análise esses conceitos convergem: poder-se-ia dizer que eu me mobilizo para alcançar um objetivo que me motiva e que sou motivado por algo que pode mobilizar-me. Mas o termo mobilização tem a vantagem de insistir sobre a dinâmica do movimento.

Charlot (2000) complementa sua colocação afirmando que não se pode dissociar "dentro" e "fora" do indivíduo. Para reforçar sua ideia recorre a Terrail (1987) para dizer que "A 'disjunção da interiorização da exterioridade e da exteriorização da interioridade’ é impossível.” (TERRAIL, 1987 apud CHARLOT, 2000, p. 58).

Ainda em relação à mobilização, Charlot (2000, p. 55) traz que "Mobilizar é pôr recursos em movimento, mobilizar-se é reunir suas forças, para fazer uso de si próprio como recurso." Além disso, é também se engajar em uma atividade originada por móbiles, devido ao fato de existirem, como nos traz o autor, "boas razões" para fazê-lo, pois são os móbiles da mobilização que produzem a movimentação, logo a entrada em atividade.

Segundo o autor, "O próprio móbile não pode ser definido senão por referência a uma atividade: a atividade é um conjunto de ações propulsionadas por um móbil e que visam a uma meta." (LEONTIEV, 1975; ROCHEX, 1995 apud CHARLOT, 2000, p. 55). Durante a atividade, implementamos ações e são essas ações que nos permitem alcançar a meta, que é o resultado dessas ações realizadas. No entanto, o móbil deve ser distinguido da meta, pois o móbil “[...] é o desejo que esse resultado permite satisfazer e que desencadeou a atividade." (CHARLOT, 2000, p. 55).

Para análise das possibilidades de interação, inicialmente, lançamos mão das ideias de Primo (2008, p. 13), quando diz que "[...] alguns pesquisadores preferem tentar diferenciar interação e interatividade. Por outro lado, tal empreitada 
converte-se em uma cilada." O autor adota em sua obra o posicionamento de que tanto um clique num ícone na interface quanto uma conversação na janela de comentários de um blog representam interações e se preocupa em diferenciá-las qualitativamente. Aponta que o que acontece, muitas vezes, é que se faz uma adoção acrítica do termo interatividade, sendo este rótulo muito utilizado em discussões sobre cibercultura. Observa que o termo, contudo, é impreciso e escorregadio, exigindo cuidado teórico em sua adoção. Silva (2001) recorda que o termo interatividade surgiu na década de 1970, um período em que se criticava a mídia unidirecional, virando moda a partir de meados dos anos $1980 \mathrm{com}$ a chegada do computador com múltiplas janelas (Windows) em rede, as quais não se limitam à transmissão, mas permitem ao usuário o "adentramento labiríntico e manipulação de conteúdos" (SILVA, 2001, p. 1).

O autor ainda explicita que a disposição interativa torna possível ao usuário ser ator e autor e que a comunicação não ocorre somente pela via da emissão, mas, também, na forma de cocriação. A interatividade possibilita ultrapassar a condição de espectador passivo para a condição de sujeito operativo. Contudo, para que efetivamente haja interatividade duas condições são necessárias: "1. A dialógica que associa emissão e recepção como pólos antagônicos e complementares na cocriação da comunicação; 2 . A intervenção do usuário ou receptor no conteúdo da mensagem ou do programa abertos a manipulações e modificações." (SILVA, 2001, p. 5).

Silva (2010) inicia seu texto apresentando três reações frequentes ao termo interatividade: a primeira reação diz respeito à simples aplicação do termo "da moda" para exprimir a ideia de velhas coisas, como diálogo e comunicação; a segunda reação diz respeito à interatividade relativa à ideologia, publicidade, estratégia de marketing, etc.; na terceira reação enquadram-se os que afirmam jamais se iludir com a interatividade homem-computador, pois têm a ideia da existência de rivalidade e dominação da técnica sobre o homem, promovendo a regressão do homem à condição de máquina. Frente a isso, o autor convida a conhecer e dialogar com outra versão para interatividade, versão que a toma como modalidade comunicacional, que parte da verificação de que o período em que estamos vivendo "[...] opera uma significativa modificação na esfera das comunicações: a transição da modalidade comunicacional massiva para a modalidade interativa." (SILVA, 2010, p. 9-10, grifo do autor).

Frente a essa nova versão, Silva (2010) trata dos fundamentos da interatividade e destaca três binômios: participação-intervenção, bidirecionalidade-hibridação e permutabilidade-potencialidade. Enfatiza que esses binômios são tomados na tentativa de sistematizar o mapeamento de especificidades e singularidades, mas de forma alguma devem estandartizar o conceito de interatividade 
em três fundamentos estanques, porque se trata de aspectos distintos que combinam e dialogam e que não são independentes.

O autor salienta que podemos revitalizar nossa função docente construindo em cada situação de aprendizagem a expressão dos fundamentos da comunicação interativa:

- Participação-intervenção. O professor pressupõe a participação-intervenção do receptor. Essa participação não se limita a responder "sim" ou "não", é muito mais do que escolher uma opção dada, é muito mais do que fazer uma pergunta. Participar é interferir em sua mensagem, é construir coletivamente a comunicação e a aprendizagem.

- Bidirecionalidade-hibridação. Comunicar pressupõe bidirecionalidade entre professor e aprendiz. A comunicação é produção conjunta dos interlocutores. Diante dos conteúdos de aprendizagem, os dois polos codificam e decodificam, colaboram e cocriam.

- Permutabilidade-potencialidade. O professor oferece múltiplas redes articulatórias para a construção da comunicação e do conhecimento. Não propõe um conteúdo fechado; ao contrário, oferece informações em redes de conexões, permitindo ao aprendiz ampla liberdade para permutar, virtualizar, simular, associar e significar. (SILVA, 2010, p. 254).

Ainda, conforme já mencionado, Prado e Rosa (2008, p. 174) citam que "Na interatividade, a "ação" ganha destaque em sua própria essência conceitual: inter-ação.” Em novas modalidades comunicacionais como chats, MSN, Orkut, entre outros, ocorre uma fusão de papéis e de funções que ultrapassam o ato de troca, possibilitando novas formas de comunicação, em que há participação ativa dos interagentes. Ou seja, em atividades didáticas com a utilização de chat, a fala dos professores pode ser recomposta e reorganizada sob o impacto das intervenções do aluno. O diálogo entre professor e aluno e entre os alunos é garantido, dependendo do encaminhamento pedagógico que se imprima à atividade. Segundo Silva (2006, p. 31), “[...] devemos nos preparar para perder a hegemonia da transmissão e da avaliação fechadas." Em concordância com Silva (2006) afirmarmos que o ambiente virtual pode se tornar auxiliador de uma outra forma de aprender. Dizemos isso em função do seguinte extrato de texto do referido autor:

No ambiente de aprendizagem online, precisaremos propor conteúdos de aprendizagem como obra aberta na qual a imersão, a navegação, a exploração e a polifonia possam fluir na lógica da completação, ou seja, de modo a permitir ao aprendiz completar e não meramente contemplar. (SILVA, 2006, p. 33).

Essas colocações vão ao encontro das palavras de Kenski (2003, p. 129) ao afirmar que os novos processos de interação e comunicação no ensino, 
mediados por tecnologias objetivam ir além da relação entre ensinar e aprender. "Orientam-se para a formação de um novo homem, autônomo, crítico, consciente da sua responsabilidade individual e social, enfim, um novo cidadão para uma nova sociedade."

Thompson (2004, p. 77) traz à cena as interações face a face, e as circunstancia como as que ocorriam em maioria até o advento do desenvolvimento tecnológico dos meios de comunicação. Se observarmos as interações na esfera educativa, de fato, o ambiente espaço-temporal era determinante para estas ocorrências. Com o desenvolvimento dos meios de comunicação, a interação se dissocia do ambiente físico, possibilitando aos indivíduos interagir uns com os outros, mesmo não compartilhando do mesmo ambiente espaço-temporal. Os meios de comunicação propiciam outras formas de interação que se estendem no espaço e no tempo, oferecendo uma gama de características que as diferenciam das interações face a face. Thompson (2004) aborda a questão comunicacional da interação e argumenta sobre o potencial dialógico nos meios tradicionais, em que o autor parte da interação face a face contrastando-a com a interação mediada. O autor propõe três tipos ou formas de interação para explorar os tipos de situação interativa fundadas pelos meios de comunicação: interação face a face, interação mediada e quase interação mediada.

Segundo Thompson (2004, p. 78), “[...] a interação face a face acontece num contexto de co-presença; os participantes estão imediatamente presentes e partilham um mesmo sistema referencial de espaço e de tempo". No entanto, este tipo de interação se restringe a um determinado espaço físico, tendo em vista que sua transmissão depende da simultaneidade geográfica ou de deslocamento(s) de indivíduos de um lugar a outro. Nas outras duas, tem-se a separação dos contextos, e a disponibilidade de ocorrência de comunicação é estendida no tempo e no espaço, ou seja, pelos meios de comunicação, a interação se dissocia do ambiente físico, de tal forma que faz possível os indivíduos interagirem entre si, sem estarem em um mesmo ambiente espaço-temporal.

Interessa-nos, nessa pesquisa, a análise realizada pelo autor referente à presença ou não da característica interativa dialógica, característica que se faz presente nas interações face a face. Julgamos que essa análise pode ser estendida às interações mediadas pelo fato de que essas "[...] geralmente implicam ida e volta no fluxo de informação e comunicação; os receptores podem responder (pelo menos em princípio) aos produtores, e estes são também receptores de mensagens que lhe são endereçadas pelos receptores de seus comentários". (THOMPSON, 2004, p. 78). Na interação mediada, o diálogo pode acontecer entre indivíduos situados remotamente no espaço, no tempo, ou em ambos, como é o caso de conversas escritas via chats. Esses dois tipos de interação ocorrem ou podem ocorrer na escola no decorrer das aulas havendo a possibilidade de 
constituírem-se em um movimento dialógico entre professor e alunos, e entre alunos.

Interessante dialogar com Scherer (2005), que, por sua vez, traz dizeres de Morin para concluir seu próprio pensamento. Diz a autora:

[...] No movimento dialógico, o educador ou educadora, em alguns momentos também irá, além de comunicar, informar, no entanto, ele ou ela informa a partir de uma problematização do conteúdo em torno do qual irá fornecer esta ou aquela informação. E estas informações não são acabadas, mas passíveis de serem investigadas com ou pelos estudantes, ou seja, o diálogo não se encerra ao informar. Afinal, o que se deseja é uma cabeça bem feita e não uma cabeça bem cheia que reproduza a educação bancária. (SCHERER, 2005, p. 84).

Apropriada a captação que a autora fez de palavras de Morin (2001, p. 21) para dar sentido educativo ao que está dissertando. Quando a autora refere-se aos termos cabeça bem feita e cabeça bem cheia, faz referência a Morin (2001, p. 21 apud SHERER, 2005, p. 85) que afirma que uma cabeça bem cheia "[...] é uma cabeça onde o saber é acumulado, empilhado, e não dispõe de um princípio de seleção e organização que lhe dê sentido.” Já, uma cabeça bem feita “[...] significa que, em vez de acumular o saber, é mais importante dispor ao mesmo tempo de: uma aptidão geral para colocar e tratar os problemas; [e] princípios organizadores que permitam ligar os saberes e lhes dar sentido."

Ainda referente à interação, adotamos Primo (2008) tendo em vista que o autor propõe a interação mediada por computador. O referido autor entende interação como "ação entre" os participantes do encontro (inter+ação) e discute a interação como movimento ocorrido entre os sujeitos, entre o sujeito e o computador e entre duas ou mais máquinas. Dessa forma, o que é proposto é a negociação de diferenças em conversações online ocorridas pela interação mútua e a reativa. Segundo Primo (2008, p. 149) “[...] as interações mútuas se desenvolvem em virtude da negociação relacional durante o processo, as interações reativas dependem da previsibilidade e da automatização das trocas".

Nas interações mútuas, o processo é dinâmico, pois são buscadas as relações entre sujeitos, que se tornam mais complexas por meio dos equilibrios e desequilibrios enfrentados pelos interagentes ${ }^{5}$, ou seja, os participantes da interação. Importante observar que "[...] quando se fala que o processo em interação mútua é dinâmico, não se pode pensar que seja apenas movimento. Tal ideia contemplaria relações meramente causais e lineares” (PRIMO, 2008,

\footnotetext{
${ }^{5}$ Segundo Primo (2008, p. 56), interagente trata-se de uma tradução livre do conceito de interactant, termo utilizado em pesquisas de comunicação interpessoal. $\mathrm{O}$ autor utiliza interagente no sentido de evitar termos reducionistas, como usuário, emissor e receptor.
} 
p. 116). O autor enfatiza a característica de a interação mútua ocorrer como ação conjunta entre os interagentes e não como uma soma de ações individuais. Como diz, interação mútua é muito mais que mero movimento ou reação determinada. De acordo com Primo (2008, p. 101-102, grifo do autor), entende-se "[...] pelo princípio sistêmico de não-somatividade que esse tipo de interação é diferente da mera soma de ações ou das características individuais de cada interagente (diz-se até que a interação é mais que a soma de seus elementos constituintes)". Refere-se ao entrelaçamento ou imbricação das ações ou das características individuais de cada sujeito da interação.

Ao processo dinâmico da interação mútua proposta por Primo, podemos entrelaçar a aprendizagem cooperativa anunciada por Scherer (2005, p. 90):

[...] no movimento de aprendizagem cooperativa é necessário o reconhecimento do outro como legítimo outro. É na aceitação mútua, na abertura para que o outro também exista em coexistência conosco, que é possível o trabalho em equipe, ou seja, a cooperação que pode levar ao consenso. E nessa relação de cooperação com o outro, busca-se seduzi-lo ao invés de submetê-lo a nossa opinião, na qual cada um aceita ou incorpora o outro domínio como parte sua, passando para este sem negar a si mesmo.

Primo (2008) concebe a interação reativa como uma relação mediada por programação, pelo fato de ser uma interação entre ser humano e computador. São as máquinas por meio de programas que determinam o formato das trocas e a emissão dos resultados a partir de um modelo previamente estabelecido e testado. Ainda, segundo o autor:

Uma interação reativa pode repetir-se infinitamente numa mesma troca: sempre os mesmos outputs para os mesmos inputs. E tal troca pode até ser testada antes mesmo da interação ocorrer, isto é, todos os botões e menus do software podem ter seu funcionamento aferido pelo próprio programa de autoria que gera antes de ser usado pelos consumidores. (PRIMO, 2008, p. 149-150).

Ainda com relação à interação, compactuamos com a ideia de Kenski (2003) quando a autora afirma que para que a aprendizagem se constitua é fundamental a interação entre as pessoas e as informações. A transformação das informações em conhecimento se estabelece no processo de discussão, reflexão, em suma, interação com outros por meio da linguagem.

Nessa pesquisa, a interação é assim concebida para fins de análise: a relação entre sujeito e objeto do conhecimento (o meio e o conteúdo) e a relação entre sujeitos da aprendizagem (os alunos). O meio aqui está representado pelo chat e pelo diário, recursos disponíveis no AVA "Curso: Educação Matemática", hospedado na plataforma Moodle e o conteúdo pela Resolução de Problemas, 
um dos conteúdos de fundamentação teórica abordados na disciplina de Metodologia do Ensino de Matemática.

\section{Ambiente virtual de aprendizagem e espaço presencial com interação e mobilização: viabilidade pedagógica}

O recorte neste artigo se dá sobre a mobilização de conhecimentos curriculares numa perspectiva de prática pedagógica em interações estabelecidas com o uso do chat e do diário em um curso de licenciatura na modalidade presencial. A pesquisa ocorreu em três etapas: houve atividades no espaço presencial (resolução de problemas matemáticos durante as aulas), no espaço virtual (identificação do referencial teórico sobre Resolução de Problema como metodologia de ensino) e no espaço presencial (discussão sobre a identificação numa perspectiva pedagógica).

Em dias posteriores à atividade nas aulas presenciais em que resolveram problemas $^{6}$, ocorreram as atividades no chat e as postagens no diário. A questão mobilizadora do chat foi: "Que relações você consegue estabelecer entre o modo como você resolveu os problemas em sala de aula com a teoria que você já estudou sobre o assunto Resolução de Problemas?” A questão mobilizadora do diário foi: "Registre nesse espaço suas primeiras impressões a respeito das atividades desenvolvidas nos dias: 09 e 16 de novembro (atividade enfocando a resolução de problemas, desenvolvida em sala de aula), 18 de novembro (atividade que fez uso da ferramenta chat disponível no Ambiente Virtual de Aprendizagem - AVA Moodle), 25 de novembro de 2010 (discussão/debate embasado no chat), descrevendo dificuldades e/ou facilidades que teve no desenvolvimento de cada uma, conhecimentos lembrados, conhecimentos aprendidos, e outros itens que você queira comentar. Boas reflexões".

Não propusemos outras questões prévias. A partir daí houve o diálogo entre os alunos e outras questões surgiram no decorrer das interações durante as atividades, em função de temáticas que emergiram das vozes dos alunos. Assim o fizemos para que os alunos não perdessem a espontaneidade nos diálogos. Se perdessem, estaríamos utilizando o chat e o diário como recurso didático inovador em um curso presencial, mas repetindo, em chat, a prática passiva de resposta à questionário, impossibilitando verificar a ocorrência, ou não, da potencialidade didática que estávamos a investigar ${ }^{7}$. Afinal, compactuamos com Scherer (2005),

\footnotetext{
${ }^{6}$ Extraídos da Olimpíada Brasileira de Matemática: <http://www.obm.org.br/opencms>.

${ }^{7}$ Guérios (2002) constatou em suas pesquisas que inovações acompanhadas de práticas antigas ou tradicionais não surtem efeito pedagógico e que, mais importante que recursos é a ação didática dos professores, esta sim, inovadora na utilização de recursos e de métodos. Ou seja, que recursos inovadores não produzem, por si, práticas inovadoras.
} 
no sentido que atribui à expressão "ousadia ao educar" quando a traz para a prática pedagógica, e com Guérios (2002, p. 165) sobre "as certezas e incertezas, o previsível e o imponderável, o conhecido e o desconhecido" que, no dizer da autora, conferem autenticidade a uma prática pedagógica inovadora. Do mesmo modo, os alunos postaram no diário suas percepções, dúvidas e o que lhes foi pertinente.

Como ato prévio, tomamos conhecimento de todo o referencial teórico estudado pelos alunos na disciplina Metodologia do Ensino de Matemática e inteiramo-nos das atividades que já haviam desenvolvido referente à Resolução de Problemas. Assim o fizemos para podermos identificá-los, caso fossem mobilizados durante as atividades no chat e no diário.

A apresentação dos indícios de interação e de mobilização de conhecimentos verificados no processo de análise está nos fragmentos selecionados a seguir. Em algumas passagens, mantivemos os horários das intervenções como estratégia para que o leitor possa dimensionar o movimento dos alunos e a cadência que imprimiram à atividade. $\mathrm{Na}$ sequência, o primeiro fragmento.

20:17 Sandra: como vocês fizeram para me dizer ro que éResolução de Problemas?AJM respondeu: 20:18 AJM: simplesmente escrevemos. Após ele escreve 20:19 AJM: de todo o conteńdo adquirido através da faculdade e leitura realizado, e comdplementa: 20:19 AJM: debates escolares. 20:19 Sandra: pensaram em algum autor? 20:19 Vane: eu pensei nas coisas que eu já li, mas em nenbum autor especifico. 20:20 AJM: Eu particularmente faço um MIX entre todos os autores lidos e formulo uma ideia que para mim seja válida. E a conversa seguiu seu curso. $\mathrm{Na}$ sequência pudemos identificar se quando AJM disse fazer um MIX entre os autores lidos, estava repetindo autores ou sintetizando ideias compreendidas. Desconfiamos da segunda situação pela expressão "formulo uma ideia que para mim seja válida". Ou seja, não estava se referindo a uma ideia qualquer, mas a alguma que por seus critérios teóricos fosse válida. Como os alunos já tinham resolvido os problemas em sala de aula e agora o objetivo era a investigação sobre a mobilização de conteúdos pedagógicos, ou seja, a Resolução de Problema como metodologia de ensino, sigamos na análise dos dados.

A interação mútua conforme Primo (2008) foi fator presente na circunstância em que os alunos discutem sobre as etapas para resolver problemas propostas por Polya (1995) ${ }^{8}$ : 21:48 Darciano: $1^{a}$ compreenda o problema, $2^{a}$ monte uma estratégia, $3^{a}$ execute a estratégia, $4^{a}$ revise. Na sequência, questionamos. 21:49 Sandra: e vocês ao resolver os problemas utilizaram quais delas? Ou não usaram? Então a discussão segue. 21:50 Tiago: utilizamos sim. 21:50 Darciano: $1^{a}$ e $2^{a}$. 21:50 Lisiane: todas acredito. 21:50 Taiana: utilizamos todas. 21:50 Darciano: a última são poucos

\footnotetext{
${ }^{8} 1^{\mathrm{a}}$ etapa: compreensão o problema. $2^{\mathrm{a}}$ etapa: construção de uma estratégia de resolução. $3^{\mathrm{a}}$ etapa: execução da estratégia. $4^{a}$ etapa: revisão da solução, ou retrospecto.
} 
que fazem! 21:51 Sandra: vocês chegaram a faz̧er o retrospecto - a revisão? 21:51 Tiago: compreendemos primeiramente o problema e posteriormente tentamos resolve-lo utilizando de alguma forma uma estratégia. 21:51 Lisiane: sim. 21:51 Taiana: sim. 21:51 Lisiane: fizemos sim, até porque queriamos ter certeza do que estava sendo feito. 21:54 Darciano: mas isso não é revisar para Polya, você está Lisiane na $3^{a}$ etapa, em que vemos se o processo está correto. 21:54 Darciano: ou se está errado. 21:55 Lisiane: por que na $3^{\circ}$ etapa? 21:56 Darciano: porque é na $3^{a}$ etapa que ocorre isso que você falou. 21:56 Lisiane: não acho, nós já tínhamos terminado o problema e não tínhamos certeza se estava correto, então revisamos ele.

No fragmento apresentado é possível observar que Lisiane está convicta de ter executado a $4^{\mathrm{a}}$ etapa. Então Darciano argumenta e a discussão continua: 21:57 Darciano: na última etapa, você tem que analisar e compreender o processo de resolução, se vai te ajudar a resolver futuros problemas. 21:58 Sandra: alguém concorda com a colocação do Darciano? 21:58 Lisiane: eu não vejo assim. 21:59 Sandra: por quê? 22:00 Lisiane: bem na verdade eu imagino revisão com um conceito diferente, mas pra ser bem sincera tenho péssima memória, então não estou me baseando em livros pra falar isso. 22:01 Lisiane: portanto não tenho argumentos. 22:01 Lisiane: nos ajude Prof. ${ }^{a}$ Celine!!!!

Observando os fragmentos das interações entre Darciano e Lisiane e a pesquisadora como mediadora, é possível observar que Lisiane já não está mais convicta, como no início da discussão, sobre as etapas propostas por Polya (1995). Quando Darciano afirma convictamente que a afirmação de Lisiane corresponde à $3^{a}$ etapa, ela não concorda, categoricamente, com tal afirmação. Ao ser questionada, justifica não ter memorizado os referenciais teóricos da disciplina, mas afirma que "imagina" "revisão" com um conceito diferente. Este "imaginar" está instituído de um juízo de valor acerca do que chama de "conceito" acerca de revisão. Neste momento, está havendo uma discussão conceitual entre a $3^{\mathrm{a}}$ (execute a estratégia), $4^{\mathrm{a}}$ (revise) etapa, inclusive sobre o próprio significado semântico das palavras "executar" e "revisar".

Seguindo com o extrato, observa-se que Darciano permanece convicto em suas colocações e termina seu pensamento. 22:02 Darciano: porque esse problema resolvido vai poder ajudar a resolver possiveis futuros problemas então você tem que compreender bem o processo se é valido para toda situação contendo as mesmas condições. 22:03 Sandra: então... Vocês acham que a forma como foram feitas as atividades com vocês era Resolução de Problemas? A conversa seguiu seu curso.

Se olharmos para o interior desse fragmento, para as nuances das "falas", observa-se que os alunos colocaram-se em movimento para aprender (CHARLOT, 2000) e que a interação no chat propiciou a discussão teórica sobre o conteúdo curricular, caracterizando a ocorrência de mobilização de conhecimento teórico sobre Resolução de Problemas ministrado nas aulas da 
disciplina Metodologia do Ensino de Matemática, sendo visível o processo de aprendizagem dos alunos. O intuito do último questionamento do fragmento foi saber como os alunos estavam interpretando, à luz do conhecimento teórico da própria disciplina. Ou seja, se as atividades de resolução de problemas desenvolvidas no espaço presencial caracterizavam ou não a Resolução de Problemas como metodologia de ensino. Ao final da conversa, concluíram que o que fizeram em sala de aula não caracterizou a Resolução de Problemas como metodologia de ensino, mas sim, apenas o ato de resolver problemas. À mesma conclusão, chegaram outros alunos em outra atividade no chat.

No fragmento a seguir é sintomático o quanto os alunos sentiram-se autônomos nas atividades via chat. Não havia um deles responsável por dar início à conversação tampouco por conduzir a atividade. No entanto, observe-se a ansiedade manifesta por AJM que inicia a conversação antes mesmo de Josa e Mi cumprimentá-los, escrevendo “então vamos começar?", sendo sequenciado por Vane com a pergunta geradora do chat.

19:58: AJM entrou no chat. 20:03: Vane, Josa e Mi entraram no chat. 20:04: AJM: oi vocês. 20:04: Vane: oi vocês. 20:04: Vivi: oi vocês. '20:04: AJM: então vamos começar?'20:04: Vivi: sim, sim. 20:05: Josa: tudo bem?. 20:05: Mi: esperem que eu não disse oi ainda. 20:05: Vane: então: que relações você consegue estabelecer entre o jeito como você resolveu os problemas em sala de aula com a teoria que você já estudou sobre o assunto Resolução de Problemas?. 20:05: Vivi: calma a Mi não disse oi ainda. 20:05: AJM: eu acho que o que tivemos na sala de aula não se trata de Resolução de Problemas, uma vez que a Resolução busca introduzir um novo conceito, visando aprendizagem. 20:05: Mi: agora eu já disse.

Primo (2008, p. 57) afirma que “[...] os interagentes transformam-se mutuamente durante o processo [...]. Pode-se afirmar que se torna impossível prever o que acontecerá nessas interações [...] chamadas de mútuas [...]”. No entanto, para que se possa entender "[...] o processo de interação mútua é preciso evitar a observação exclusiva no comunicador individual." (PRIMO, 2008, p. 102). Por outro lado, as interações (1) o clicar em um link e (2) o utilizar-se do teclado e do mouse do computador, denominadas interações reativas, "[...] são limitadas por certas determinações e, se a mesma ação fosse tomada uma segunda vez (mesmo que por outro interagente), o efeito seria o mesmo.” (PRIMO, 2008, p. 57). Ou seja, a interação reativa se dá numa cadeia linear, "[...] onde uma ação A causa necessariamente uma reação R [...].” (PRIMO, 2008, p. 107). Primo salienta que a interação mútua deve ser compreendida em contraste à interação reativa, que é um tipo de reação mecânica. "A palavra 'mútua' foi escolhida para salientar as modificações recíprocas dos interagentes durante o processo. Ao interagirem, um modifica o outro". (PRIMO, 2008, p. 57). 
Mediante o exposto é possível inferir que, enquanto os sistemas informáticos se guiam por algum dado considerado correto ou verdadeiro para que possa ocorrer a interação, interagentes em interação mútua, mesmo tendo certas convicções, poderão debater assumindo posições diferentes, reconsiderando suas certezas temporárias e até mesmo incorrer em contradições sem que isso afete, obstaculize ou impeça a interação, fato que acontece em interações reativas perante alguma troca imprevista.

O que acabamos de mencionar é possível de ser verificado no seguinte fragmento, particularmente na fala de AJM. 20:05 AJM: eu acho que o que tivemos na sala de aula não se trata de Resolução de Problemas, uma vez que a Resolução busca Introduzir um novo conceito, visando aprendizagem. 20:07 Vane: eu não concordo, acredito que há várias maneiras de se trabalhar por meio da resolução de problemas. 20:07 Josa: eu concordo com a Vane. 20:08 Mi: nós estávamos aplicando o que já aprendemos em outro momento. 20:09 AJM: foi interessante o problema abordado, porém foge da essência da Resolução, pois somente a apresentação de um problema não basta, necessita de um momento de reflexão sobre o problema. 20:11 Mi: mas nós refletimos sobre eles não refletimos. 20:13 Josa com certeza, mas como nós queríamos resolver este, então é resolução de problema.

Anteriormente a afirmação "faço um MIX... e formulo uma ideia que para mim seja válida" nos instigou a investigar em que base a fazia. Essa afirmação posterior, em outra circunstância, demonstra que, de fato, AJM estava mobilizando conhecimentos da disciplina. Sua fala é conclusiva, neste momento. As discordâncias entre eles, algumas frontalmente opostas, não se chocam para cada um deles, que estão em momento próprio de construção conceitual dos conteúdos pedagógicos curriculares. Mi, por exemplo, tem um entendimento aplicacionista dos conteúdos, embora afirme que houve reflexão no ato da resolução dos problemas no espaço presencial, com o que Josa diz concordar, embora sua justificativa vá em outro sentido. É possível, inclusive desconfiar que, neste momento da atividade, Josa não faz diferença entre o ato de resolver problema e a discussão da Resolução de Problema como metodologia de ensino. Na sequência, por processos interativos, a discussão tomou outros rumos.

Se analisarmos os fragmentos à luz de Silva (2010), observamos que os binômios por ele propostos fazem sentido em nossa investigação. Assim, se no binômio participação-intervenção pressupõe-se uma participação que extrapola emitir simples respostas imediatas ou apenas fazer pergunta, se participar é interferir em uma mensagem e construir coletivamente a comunicação e a aprendizagem, então os registros dos fragmentos evidenciam tal ocorrência. As relações que se foram estabelecendo no movimento presencial-virtual-presencial visibilizam o próprio processo de construção conceitual. Basta percorrer os diálogos estabelecidos para verificar que entre o sim e o não das afirmações que se foram efetivando, estão os indícios de construção conceitual. Se o binômio 
bidirecionalidade-hibridação caracteriza-se pela codificação, decodificação, colaboração e cocriação como características de uma comunicação que é produção conjunta de interlocutores, então se pode dizer que as atividades no chat foram berço para a geração de argumentos estruturantes do pensamento dos alunos. Se no binômio permutabilidade-potencialidade o professor não propõe conteúdo fechado possibilitando ao aluno ampla liberdade para permutar, virtualizar, simular, associar e significar, então quando os alunos discutiram, o fizeram, exatamente porque tal circunstância lhes estava sendo permitida. E ao ser, deu-se-lhes voz, que foram ouvidas. Se analisarmos as falas dos alunos e da pesquisadora quando em sua atividade de mediação teve voz, e, compararmos com as respostas, redigidas a seguir, para a pergunta "o que vocês entendem por Resolução de Problemas?” percebemos que as atividades com o chat associadas às atividades no espaço presencial, em conjunto, possibilitaram a elaboração de respostas como somatória refletida de um conjunto de diálogos dos alunos mediados pela pesquisadora. Um exemplo do conjunto da ocorrência dos três binômios é quando Eli diz "analisando a ideia do Darciano, foram Problemas". É o outro presente na construção de uma ideia a partir de situação de aprendizagem aberta e participativa.

As respostas para a pergunta foram:

AJM: Resolução de Problemas é um método de introduzir um novo conceito, através do debate sobre um problema inicial... Onde esse problema recairá no conceito abordado.

Vivi: Resolução de Problemas é uma tendência da Educaşão Matemática para tentar tornar as aulas de Matemática mais dinâmicas e interessantes aos alunos. Quer dizer a Resolução de Problemas é uma metodologia.

Vane: Resolução de Problemas é uma estratégia de ensino que contribui para a prática docente, bem como, pode despertar o interesse dos alunos, desenvolvendo competencias e habilidades matemáticas. [...].

AJM: O aluno comeca tentando resolver um problema geralmente colocado pelo professor; ao ver que os conbecimentos dos alunos ainda são insuficientes, o professor deve então, a partir deste momento, interferir, introduzindo um novo conceito...

Mi: a resolução de problemas requer o envolvimento do aluno, busca despertar seu interesse.

Até o momento, por opção didática para este artigo, delimitamos os fragmentos e a discussão em conteúdos sobre Resolução de Problemas, conforme Polya. No entanto, no decorrer das atividades os alunos foram mobilizando conhecimentos dos demais autores que haviam estudado nas aulas presenciais, conforme ilustramos com AJM e Vane. AJM: na parte da reflexão sobre o assunto, ao invés de fazer um relato ou resumo, realizar um mapa com palavras chave. Vane: podemos pedir para que os alunos elaborem um mapa sobre as coisas trabalhadas, estratégias utilizadas, na elaboração da atividade em questão [referiam-se a mapas conceituais]. 
Nesta pesquisa, o diário caracterizou-se como um registro em movimento das primeiras impressões que os alunos tiveram com relação à realização das atividades. Este recurso teve o objetivo de registrar as reflexões dos alunos e, perante os registros postados foi possível perceber que esse recurso é um auxílio para a avaliação porque visibiliza o processo de aprendizagem individual do aluno. Por exemplo, Eli registra a seguinte reflexão sobre o entrelaçamento da solução do problema que resolveu com o conhecimento teórico sobre Resolução de Problema como metodologia de ensino:

Eli: Em relação às primeiras atividades desenvolvidas, foi muito interessante, pois embora durante as aulas nossos conhecimentos em relação à Resolução de Problemas, fosse discutida baseada na teoria, na prática é muito mais legal. Pois, pensamos maneiras diferentes de resolver, nos empolgamos achando que estávamos no caminho certo, quando chegamos na metade nos deparamos que as análises iniciais não eram válidas. Somente no segundo encontro que possibilitou a visualização de mudarmos a condição que finalmente foi o que fez. supostamente o "barco" andar.

Conforme já apontamos, após as atividades no espaço presencial e no virtual, houve o retorno das atividades no espaço presencial. Ao início da atividade, perguntamos se havia algum ponto que julgassem necessário retomar daquele chat. Tiago toma a dianteira: "acho que aquela parte da... só a parte da terceira e quarta etapa... é que o Darciano e a Lisiane, aquela parte sabe, que realmente não tá claro... o que realmente cai na terceira etapa e o que cai na quarta etapa, acho que isso ficou meio aberto...". Darciano então diz: "não é que o seguinte, quando a gente tá se referindo ao Polya, ele propõe o seguinte: ele propõe as quatro etapas, na terceira etapa ... você analisa se os dados, no caso o aluno vai analisar se os dados, se o processo que ele fez está correto, se... encontrando algum erro ou não. E, na última etapa não, ele vai ... analisar se esse processo que ele encontrou pra resolver tal problema, pode ser utilizado num... pra resolver um problema futuro ou .... [...] Mas, é mais ou menos isso.... você analisa não na questão de revisar ... analisar se os dados, se o processo tá certo on tá errado, essa é a terceira etapa... [...]."

Podemos fazer um link entre essa colocação de Darciano na retomada da atividade no espaço presencial e o chat. Durante este chat, Tiago foi um dos alunos que respondeu "utilizamos sim", ou seja, afirmou que ele e seu grupo haviam utilizado as etapas de Polya para resolver os problemas propostos. Já na retomada da atividade no espaço presencial Tiago diz: "na verdade a gente revisou praquele caso, mas não... [...] não que nem o Darciano conton que fosse pra algum caso diferente, acredito eu que pra algum caso semelhante até... até funcionaria, mas isso não veio na nossa cabeça, veio... nosso objetivo era resolver o problema... [...] aquele problema... a gente não pensou num problema que seja parecido ou alguma coisa assim... a gente tava preocupado com aquele problema, então, pelo que o Darciano falou a gente parou na terceira etapa que... ali só deu aquela revisada que, fechon aqui, fechou... beleza." 
No fragmento apresentado é possível perceber que a ocorrência da interação mútua (PRIMO, 2008) fomentou discussões que levaram os alunos a rever a construção conceitual que estavam efetivando, até aquele momento. Inicialmente Tiago havia pensado que ele e seu grupo tinham usado as quatro etapas; no entanto, ao ouvir a explicação de Darciano observa que estava equivocado e muda de opinião, dizendo que haviam parado na terceira etapa. À vista do exposto, podemos dizer que mediante interações ocorreu a mobilização de conhecimentos do conteúdo Resolução de Problemas. Inclusive, possibilitou que todos observassem o que de fato aconteceu em termos de aprendizagem, porque o equívoco em pauta ocorreu durante os diálogos efetivados no processo de interação. A percepção dos equívocos foi positiva por visibilizar a real situação de aprendizagem dos alunos.

Embora, inicialmente, tanto Darciano quanto Tiago tenham falado que o que fizeram foi Resolução de Problemas, mediante interações e mobilização de conhecimentos do conteúdo de Resolução de Problemas, Tiago termina por afirmar que o feito caracterizou apenas Problema, ou seja, realizaram apenas a resolução dos problemas e não a caracterizaram como metodologia de ensino, tal qual Taiana em outra situação. Mediante interações, eles mudam a percepção que haviam tido e dizem perceber que focaram a resolução dos problemas sem preocupação com os encaminhamentos metodológicos.

A mobilização de conhecimentos do conteúdo Resolução de Problemas também pode ser observada quando Darciano mostrou como compreendeu e manifestou sua construção conceitual sobre a metodologia de Resolução de Problemas: "[...] com Resolução de Problemas você vai iniciar tua aula com um problema e vai chegar num conteúdo que você... talvez propos levando aquele problema pros alunos resolver, problema teórico, problema não é... você logo já conhece só vai ter que... utilizar um algoritmo e alguma coisa que resolva!".

Interessante pontuar que, com essa colocação de Darciano, Eli mobiliza-se e diz “não! Foram Problemas!". Isso ela fala prontamente quando na discussão sobre a forma como a atividade de resolver problemas caracterizou ou não a Resolução de Problemas como metodologia. Ela complementa: "analisando a ideia do Darciano, foram Problemas!".

O uso por Eli do termo "analisando" evidencia a ocorrência de um movimento para a aprendizagem que supera a simples absorção de conteúdos. Se a interação entre os alunos possibilitou a análise de um sobre a expressão do outro, então a interação pode possibilitar uma aprendizagem efetiva. Os fragmentos mostram ocorrência de mobilização de conhecimentos através de interações mútuas e provocam um movimento de aprendizagem reflexivo. Interpretando Silva (2010) em função da análise dos dados empíricos, percebemos que, como 
produção conjunta de interlocutores os alunos cocriaram e, nessa cocriação, desenvolveram estratégias pessoais de aprendizagem, significaram o conhecimento teórico sobre Resolução de Problemas na perspectiva pedagógica e o construíram como substrato conceitual.

Diante do que foi exposto até aqui, procuramos mostrar o processo interativo no qual os alunos se inseriram, em um contexto de busca e criação de estratégias próprias, levantando hipóteses, testando-as, dialogando com elementos dos problemas e com os conhecimentos teóricos já adquiridos sobre Resolução de Problemas, modificando estratégias e pontos de vista, utilizando conhecimentos matemáticos e metodológicos anteriormente adquiridos, dentre outros. Nossa intenção, neste artigo, foi verificar possibilidades de interação e mobilização de conhecimentos curriculares, matemáticos e pedagógicos, a partir da Resolução de Problemas, por alunos de um curso presencial de Licenciatura em Matemática, utilizando recursos de ambientes virtuais de aprendizagem nas aulas de Metodologia do Ensino. Identificamos essas possibilidades e as colocamos à disposição da comunidade científica e educativa.

\section{Considerações Finais}

Alunos de um Curso de Licenciatura em Matemática na modalidade presencial de uma instituição pública tiveram, em situação de prática, conhecimento sobre a cultura digital tendo o primeiro contato com os recursos chat e diário disponíveis no Ambiente Virtual de Aprendizagem (AVA) no "Curso: Educação Matemática" hospedado na plataforma Moodle, criado especificamente para as atividades desta pesquisa.

Criamos a denominação "sala de aula expandida" para simbolizar a dimensão adquirida pela expansão da aula para além do espaço físico e do tempo das aulas delimitadas no tradicional espaço presencial. Constatamos haver complementaridade entre o espaço presencial e o virtual no contexto da prática pedagógica quando ambos foram utilizados numa perspectiva de ambientes articulados, porque oportunizaram aos alunos, sujeitos da pesquisa, mais e produtivos momentos de interação e mobilização de conhecimentos referentes ao conteúdo teórico curricular da disciplina Metodologia do Ensino de Matemática envolvido na atividade por eles desenvolvida para resolver problemas matemáticos. O significado do exposto é que a sala de aula tomou uma nova conformação, a de uma sala de aula expandida.

O espaço virtual ampliou os momentos de debates e reflexões. $\mathrm{O}$ chat e o diário possibilitaram a obtenção de registros de aprendizagem ao permitirem "ouvir" detalhadamente cada um dos alunos, situação que permitiu inferir 
a possibilidade de observação e análise contínua e minuciosa do caminhar dos alunos no processo de aprendizagem em cursos de licenciatura na modalidade presencial. A utilização do chat e do diário permite ao professor e aos alunos ler tantas vezes quantas forem necessárias os registros escritos das falas, as anotações e as postagens dos participantes das atividades, num movimento que não possui um começo nem um fim, ou uma ordem pré-determinada para acontecer. Pode ocorrer mais de uma conversa ao mesmo tempo, e uma discussão pode ser retomada pelos interagentes, tanto por um professor como por um aluno. Basta acessar o AVA, a qualquer momento.

O chat permitiu que todos os interagentes tivessem voz e vez. Mesmo os "menos falantes" se pronunciaram, debateram e sustentaram seus pensamentos, interrogaram, interpelaram os colegas quando não compreenderam, discordaram e argumentaram. O diário pode ser utilizado como um registro em movimento da aprendizagem dos alunos. Em cursos presencias, permite aos professores realizar feedbacks visando à construção de uma relação cooperativa entre professores e alunos e entre os próprios alunos. Os registros postados pelos alunos favorecem o processo de avaliação contínua da aprendizagem de cada aluno, auxiliando o professor a atuar didática e pedagogicamente numa perspectiva de investigação para intervenção.

A análise dos dados empíricos mostra que as ferramentas chat e diário, disponíveis no AVA Moodle são potencializadoras de práticas pedagógicas que auxiliam no processo de ensino e de aprendizagem em cursos presenciais de Licenciatura em Matemática. Devido às ocorrências da característica interativa dialógica (THOMPSON, 2004) e de interações mútuas e reativas (PRIMO, 2008) os sujeitos da pesquisa mobilizaram conhecimentos matemáticos e pedagógicos (referenciais teóricos estudados pelos alunos na disciplina Metodologia do Ensino de Matemática) (CHARLOT, 2000; POLYA, 1995). Os sujeitos da pesquisa conseguiram chegar a uma solução, independente de esta estar correta ou não, para os problemas propostos na atividade desenvolvida no espaço presencial, uma vez que se mantiveram atentos aos enunciados e respectivas soluções no espaço virtual. Pela análise dos dados podem-se observar indícios de mobilização de conhecimentos através de interações mútuas e a existência de um movimento reflexivo de aprendizagem, tendo em vista que este movimento implicou na tomada de consciência conceitual e trocas de informações entre os pares.

Podemos dizer que os alunos demonstraram o desejo de saber e que houve mobilização, pois os alunos colocaram-se em movimento para aprender. Concluímos que houve mobilização dos conhecimentos específicos da 
temática curricular Resolução de Problemas, e todos se envolveram nas atividades, interagiram, mobilizaram conhecimentos e estabeleceram conexões entre os diversos teóricos estudados na disciplina de Metodologia do Ensino, extrapolando a discussão pontual do que estava diretamente relacionado à temática e a um autor determinado.

Dissemos no início deste artigo que os tempos atuais estão anunciando a possibilidade de haver uma simbiose entre espaço virtual e presencial na esfera educativa, oportunizando, como consequência, a ocorrência de práticas didáticas inovadoras e que a prática pedagógica, em suas diferentes nuances, pode estar no limiar da operacionalidade técnica vigente. Se, por um lado, não estamos fazendo a apologia indiscriminada e inocente do uso do espaço virtual, por outro, esta-mos colaborando com evidências sobre dados concretos para uma possível integração entre ambiente virtual de aprendizagem e educação presencial na formação de professores de matemática com vistas ao desenvolvimento de práticas didáticas inovadoras.

\section{Referências}

ALMEIDA, M. E. B. de. Educação a distância na internet: abordagens e contribuições dos ambientes digitais de aprendizagem. Educação e Pesquisa, São Paulo, v. 29, n. 2, p. 327-340, jul./dez. 2003. DOI: 10.1590/S1517-97022003000200010

ALVES-MAZZOTTI, A. J.; GEWANDSZNAJDER, F. O método nas Ciências Naturais e Sociais: pesquisa quantitativa e qualitativa. 2. ed. São Paulo: Pioneira, 2001.

BAIRRAL, M. A. Discurso, interação e aprendizagem matemática em ambientes virtuais a distância. Seropédica: Universidade Rural, 2007.

BICUDO, M. A. V. Pesquisa qualitativa e pesquisa qualitativa segundo a abordagem fenomenológica. In: BORBA, M. de C.; ARAÚJO, J. de L. (Org.). Pesquisa qualitativa em Educação Matemática. Belo Horizonte: Autêntica, 2006. p. 101-114.

BITTAR, M. A parceria escola x universidade na inserção da tecnologia nas aulas de matemática: um projeto de pesquisa-ação. In: CUNHA, A. M. de O. et al. (Org.). Convergências e tensões no campo da formação e do trabalho docente. XV ENDIPE, Minas Gerais. Belo Horizonte: Autêntica, 2010. p. 591-609.

BORBA, M. de C.; MALHEIROS, A. P. dos S.; ZULATTO, R. B. A. Educação a distância online. Belo Horizonte: Autêntica, 2007.

BROUSSEAU, G. Guy Brousseau: a cultura matemática é um instrumento para a cidadania. Revista Nova Escola, São Paulo, n. 228, dez. 2009. Disponível em: < http://revistaescola. abril.com.br/matematica/fundamentos/cultura-matematica-instrumento-para-cidadaniaguy-brousseau-calculo-518776.shtml>. Acesso em: 04 nov. 2012.

CHARLOT, B. Da relação com o saber: elementos para uma teoria. Porto Alegre: Artmed, 2000 . 
GUÉRIOS, E. Espaços oficiais e intersticiais da formação docente: história de um grupo de professores na área de ciências e Matemática. 2002. 234 f. Tese (Doutorado em Educação) - Faculdade de Educação, Universidade Estadual de Campinas, Campinas, 2002.

KENSKI, V. M. Tecnologias e ensino presencial e a distância. Campinas: Papirus, 2003. (Série Prática Pedagógica).

MORAN, J. M. Pedagogia integradora do presencial-virtual. Set. 2002. Disponível em: <http://www.abed.org.br/congresso2002/trabalhos/texto50.htm>. Acesso em: 09 abr. 2012.

Propostas de mudança nos cursos presenciais com educação on-line. Set. 2004. Disponível em: <http://www.eca.usp.br/prof/moran/propostas.htm>. Acesso em: 09 abr. 2012.

MORIN, E. A cabeça bem-feita: repensar a reforma, reformar o pensamento. 3. ed. Tradução de Eloá Jacobina. Rio de janeiro: Bertrand Brasil, 2001.

MYERS, M. D. Qualitative research in information systems. Disponível em: <http:// www.qual.auckland.ac.nz> Acesso em: 10 abr. 2012.

POLYA, G. A arte de resolver problemas: um novo aspecto do método matemático. Tradução e adaptação de Heitor Lisboa de Araújo. Rio de Janeiro: Interciência, 1995.

PRADO, E. C. do; ROSA, A. C. S. da. A interatividade na educação a distância: avanços e desafios. Eccos, São Paulo, v. 10, n. 1, p. 169-187, jan./jun. 2008. DOI: 10.5585/EccoS. v10i1.950

PRIMO, A. Interação mediada por computador: comunicação, cibercultura, cognição. 2 ed. Porto Alegre: Sulina, 2008.

SÁ, R. A. de. Educação à distância: estudo exploratório e analítico de graduação na área de formação de professores. 2007. 422 f. Tese (Doutorado em Educação) - Faculdade de Educação, Universidade Estadual de Campinas, Campinas, 2007.

SCHERER, S. Uma estética possível para a educação bimodal: aprendizagem e comunicação em ambientes presenciais e virtuais - uma experiência em estatística aplicada à educação. 2005. 241 f. Tese (Doutorado em Educação: Currículo) - Pontifícia Universidade Católica de São Paulo, São Paulo, 2005.

SCHLEMMER, E. AVA: um ambiente de convivência interacionista sistêmico para comunidades virtuais na cultura da aprendizagem. 2002. 370 f. Tese (Doutorado em Informática na Educação) - Universidade Federal do Rio Grande do Sul, Porto Alegre, 2002.

SILVA, M. Sala de aula interativa a educação presencial e à distância em sintonia com a era digital e com a cidadania. In: SOCIEDADE BRASILEIRA DE ESTUDOS INTERDISCIPLINARES DA COMUNICAÇÃO - INTERCOM; CONGRESSO BRASILEIRO DA COMUNICAÇÃO, 24., 2001, Campo Grande. Anais... Campo Grande, 2001. p. 1-20. Disponível em: <http://galaxy.intercom.org.br:8180/dspace/ bitstream/1904/4727/1/NP8SILVA3.pdf>. Acesso em: 09 abr. 2012.

. O fundamento comunicacional da avaliação da aprendizagem na sala de aula online. In: SILVA, M.; SANTOS, E. (Org.). Avaliação da aprendizagem em educação online: fundamentos, interfaces e dispositivos, relatos de experiência. São Paulo: Edições Loyola, 2006. p. 23-36. 
Sala de aula interativa: educação, comunicação, mídia clássica. 5. ed. São Paulo: Edições Loyola, 2010.

THOMPSON, J. B. A mídia e a modernidade: uma teoria social da mídia. Tradução de Wagner de Oliveira Brandão. 6. ed. Petrópolis: Vozes, 2004.

Recebido em 31/03/2012

Aceito em 29/08/2012 